Further it seems only just to add that, so early as March 27, 1871, Mr. Robert Louis Stevenson described to the Royal Scottish Society of Arts forms of intermittent lighthouse apparatus for exhibiting groups of flashes of occultations of unequal period; these arrangements, possessing the advantage over Babbage's original proposal, that during dark intervals the light is not simply stopped by a screen and thus lost, but sent usefully in other directions to strengthen the bright intervals or flashes.

Ardchapel, Dumbartonshire, September 21 WILliam SWAN

\section{The August Meteors}

As noted in NATURE, vol. xxvi. p. 378, I observed a bright display of meteors on the night of August 6, at Aberfeldy. On the 7 th the sky was overcast with dense clouds all night; - but on the following night I saw a more brilliant shower of meteors than on the 6th, with this difference that the meteors of the night of the 8th were mostly of several seconds' duration, and generally left a long, bright train of light behind; also, in place of being on the north of the Milky Way, as on the 6th, they were chiefly on the south of it. A very large and bright meteor burst out about half way to the zenith, and moved nearly horizontally from the south-east towards the west, leaving a long shining streak behind, and lasting close on fifty seconds. I watched the meteors for the next three nights from the parish manse of LogieAlmond, and witnessed on each night (9, IO, and II) a gorgeous shower. On the evening of the roth, before the twilight was quite gone, I noticed thirteen very large meteors during the space of a few minutes, although my view of the heavens was very much intercepted by trees and by the manse. Between I I and I2 o'clock a meteor considerably larger and brighter than Venus under the most favourable circumstances, sailed over the southern heavens, leaving a long train of light which lasted fully a minute. Its position, time, and appearance, were nearly the same as those of the large meteor I saw at Aberfeldy on the night of the 8th. I have not for years, during any month, witnessed such a gorgeous display of meteors as I have seen on the nights specified in August last. But I have scarcely seen any since, except a few bright ones on Sunday night, September 17, at High Blantyre. The display of the August meteors was of a very short duration on each night, and after I 2 o'clock not one scarcely could be seen.

Govanhill, Glasgow, September 2r Donald CAMERoN

\section{ANIMAL INTELLIGENCE 1}

FROM the time of Locke downwards the question How far animals have the power of abstraction? has often been discussed. Locke himself maintained that "the having of general ideas is that which puts a perfect distinction betwixt man and brutes, and is an excellency which the faculties of brutes do by no means attain to." And this view is warmly advocated by Prof. Max Müller and other living thinkers. On the other hand $\mathrm{Mr}$. Romanes, who has made the subject of Animal Intelligence a special study, writes:- "Give a cat or a dog some kind of meat or cake which the animal has never met with, and the careful examination which the morsel undergoes before it is consigned to the mouth proves that the animal has properly abstract ideas of sweet, bitter, hot, nauseous, or in general, good for eating, and bad for eating, i.e., abstract ideas of quality as apart from the object examined - the motive of the examination clearly being to ascertain which general idea of quality is appropriate to the particular object examined."-NATURE, vol. xx., p. I23.

Our first duty in a case like this is to make quite sure of the meaning of the words we employ. Much confusion may be, and has been, introduced into this subject by a lax use of words. Let us consider, then, the several meanings which these terms abstraction and abstract idea may have.

In the first place it seems to me that our most ordinary impressions involve abstraction. An object is capable of affecting us in a number of different ways, but of all

I From a Lecture delivered in Cape Town, South Africa. these at any given moment we only pay attention to one or two which happen to interest us. The rest are practically non-existent for us. The mind automatically rejects or eliminates them. This is certainly a process of abstraction, but for the sake of clearness I venture to call it elimination. By means of elimination we get definite clear-cut mental impressions.

In the second place our general conceptions involve abstraction. A general conception is one which does not stand for a particular object but for a group of objects. It is arrived at by abstracting the essentials and neglecting the unessentials. In the great number of dogs I see around me, there are certain essential characters in the midst of some diversities. As I consider them in the mass, however, the diversities cancel each other in my mind, and I obtain a general conception of a dog. We may for the purpose in hand call this process generalisation. The product is not a definite and clear-cut image.

In the third place, I may by a process of abstraction consider a quality apart from the things that possess that quality-whiteness for example, apart from white objects, edibility apart from edible things. We will here retain the term abstract idea to denote such qualities, and we will for the present term the process by which they are obtained isolation. Of a completely isolated quality no mental image can be formed.

That dogs and the lower animals in general make use of the process I have above termed elimination, cannot I think, for one moment be doubted. For if they do not then we must suppose that they are able mentally to grasp an object in the entirety of its qualities, which is more than the average human being can do. Let us suppose that a dog sees what he believes to be a soaked dog-biscuit. The impression he receives through his eyes at once suggests certain possible olfactory impressions and certain possible gustatory impressions. This of course implies what is commonly called the association of ideas. But there are other possible impressions which might be suggested but probably are not, such impressions, for instance, as may be produced by the hardness, temperature, and weight of the object. These impressions are not suggested, they are eliminated, so to speak. In other words, certain possible impressions are abstracted from certain other possible impressions. Sup pose, now, the dog proceeds to smell the biscuit that he has hitherto only seen. If it answers to his expectations he at once begins to eat it. His nose tells him that it is good for eating. If, however, it does not answer to his expectations, if, perhaps, it has received the drippings of a paraffin tin, he turns sorrowfully away. His nose tells him that it is not good for eating. One kind of smell suggests that the biscuit will be pleasant to the taste: another kind of smell suggests that it it will be unpleasant And the dog, unless he be a very young one, having confidence in his nose, acts upon the suggestions without verification. It is to these suggested impressions that Mr. Romanes applies the term "abstract ideas of quality, as apart from the object examined." And I do not suppose that any one is prepared to deny our dumb companions abstract ideas in this sense of the term.

Let us now consider how far we may suppose animals to possess the power of generalisation in the sense in which I have above used this term. A dog lying asleep upon the hearth-rug hears outside the window an unusual footstep. He at once pricks up his ears and gives a half suppressed growl. Must we not suppose that in such a case as this the footstep suggests to the dog the idea of a strange man? And if so, will not the suggestion-of whatever character it might be-be general rather than particular? If it be a mental picture--and we are often told that dogs think only in pictures ${ }^{1}{ }_{-}$-must not the picture be generic

${ }^{I} \mathrm{I}$ do not know that $\mathrm{I}$ quite understand what thinking in pictures means, but I should imagine that sounds and smells entered pretty largely into the think that Spenser and Shakespeare possessed in no slight degree the power 
in its character, like Mr. Galton's composite photographs of the average blackguard? And if it be a symbol of some kind, must it not be a symbol that stands for strange man in general, since there is nothing to suggest any particular strange man? But if this be so, and if a general conception is one which stands not for a particular object, but for a group of objects, I do not see how we can deny general conceptions, in this sense of the word, to our four-footed friends. And if the word abstract idea stand, as it is sometimes made to do, for general conception, we must admit, I think, that such abstract ideas are possible for the brute.

We come now to such abstract ideas as result from the process I termed isolation. Are these, too, possible for the brute? I have only to say that it has always seemed to me that when we speak of being able to form abstract ideas of redness, emptiness, justice, and the like, all we can possibly mean is that we can make use of the words as symbols in a train of thought I have only to say this to indicate the nature of my answer to this question, I believe such abstract ideas to be impossible for the brute, I believe them to be the outcome of the use of language We see a plum, and we find that it is round, and blue, and resisting. From these words we form abstract nouns, roundness, blueness, resistance. We then proceed to manufacture a something to which each of these words may answer, and we call that something a quality. Having thus made the quality, the next thing we do is to try and endow it with a separate existence, and to the results of our endeavours we give the name abstract idea. All this is a process which grows out of our use of words under the influence of a developed power of reflection; it is an attempt to conceive a realityin-thought answering to certain of our symbols. Without a considerably developed use of symbols such a process is impossible. Hence 1 believe that no animal can form an abstract idea in this sense of the term. He does not possess the only possible means of doing so. To form such abstract ideas as these, is certainly "an excellency which the faculties of brutes do by no means attain to." Here we may agree with Locke and his followers.

May we say, then, that the power of forming abstract ideas, in this sense, is that which distinguishes the intelligence of man from the intelligence of the brute? I think not. There are I believe, among the lower races of man, whole tribes which are unable to form abstract ideas. Abstract ideas are made possible by language, but the use of language does not necessarily imply the ability to form abstract ideas. Philologists tell us that there are languages or dialects in which no abstract words are to be found. This, however, is certain, that there is no known savage tribe which has no language. Man is the one being that can make use of spoken signs.

But it may be said that, although their language differs from ours, animals too have their language, imperfect it is true but still a language of their own, a means of communication with their fellows. And this is perfectly true. It is true, too, that my dogs can understand my language. But all that a dog can communicate to his fellow-all that I can communicate to my dog is a sign which he has learnt to associate with certain feelings or with certain actions to be performed. The communication deals, too, with immediate feeling or action; its sphere is the here and the now. There can be no doubt that dogs associate with barking in certain tones, special emotional states in their companions. In fact it is probable that dogs can in this way communicate with each other a wide range of states of feeling. But these states are present states, not states past or future. They are their own states, not the states

of thinking in pictures-pictures far truer and more beautiful than even they could describe in words. All processes of thought, in fact, are carried on by association. And in the chain of association there may be links of all kinds furnished by all the senses we possess. All that we can say with regard to man is that he adds to the natural symbols which form links in this chain of associatiun, certain arbitrary symbols of his own manufacture. of others. A dog can call his companions' attention to a worriable cat, or he may have his attention roused by my exclaiming "cat." But no dog could tell his companion of the successful "worry" he had just enjoyed or suggest that they should go out for a "worry" to-morrow morning. And here we come upon what seems to me the fact which raises man so immeasurably above the level of the brute. The brute has to be contented with the experience he inherits or individually acquires. Man, through language spoken or written, profits by the experience of his fellows. Even the most savage tribe has traditions extending back to the father's father (Sproat). And the civilised man--has he not in his libraries the recorded results of many centuries of ever widening experience and ever deepening thought? Thus it is that language has made us men. By means of language and language alone has human thought become possible. This it is which has placed so enormous a gap between the mind of man and the mind of the dog. Through language each human being becomes the inheritor of the accumulated thought and experience of the whole human race. Through language bas the higher abstract thought become possible.

But though I look upon the difference between human intelligence and brute intelligence as very great, $I$ do not believe that there is any one faculty which all men possess and which no brute possesses. I have already stated my views on the subject of abstraction, and to what I have said I have nothing now to add. But concerning the converse process of construction or object-forming a few words may be said. Let me first explain what I mean by construction. Our conception of an object is the result of a synthesis of its qualities. But this synthesis is, I inagine, of two kinds. There is a synthesis by immediate association, and a synthesis by reflection. When a dog sees before him a soaked dog-biscuit, his conception of the object is a synthesis by immediate association. The sight of the biscuit at once suggests by association a certain smell and taste. The object he mentally constructs is built up of these three, sight, smell, and taste. All other properties are rejected or eliminated. Now, suppose the dog capable of reflecting thus - the biscuit is light enough to carry, soft enough to bite, cool enough not to burn my mouth - he would then add to his synthesis by immediate association, a further synthesis by reflection, and would construct a more complete object. By the synthesis by reflection, in fact, all those qualities are added which are unconsciously eliminated in the immediate construction by association. I do not imagine that brutes have sufficient power of reflection to affect to any great extent this further synthesis. Indeed I imagine that savages and young children do not habitually go further than the construction by association. The further process has been added mainly under the influence of a developed language. The word groups around itself not only the cluster of associated ideas which make up the ordinary unreflecting conception of the object it symbolizes, but also all those further ideas which are the result of scientific study. The word is the peg upon which we hang those abstract qualities which by means of words we have isolated.

C. Lloyd MORGAN

\section{AINO ETHNOLOGY}

THE already somewhat voluminous literature of the Aino race has been recently increased by two valuable memoirs by competent original observers. ${ }^{\mathrm{I}}$ Hence if neither Dr. Scheube nor Herr von Siebold has anything very new to tell us, it may be fairly concluded that most of the available data have now been collected. Ex tended research in the unexplored districts of Yeso may doubtless bring to light some further interesting facts

I "Die Ainos," von Dr. B. Scheube, Yokohama, r882; and "Ethnolo gische Studien über die Aino auf der Insel Yeso, von Heinrich von Siebold, Berlin, $188 \mathrm{r}$ 